\title{
Hormone Receptor Status and KI67 Proliferation Index in Meningiomas
}

\author{
Rajeshwari B. ${ }^{1 *}$, Salapathi Shanmugam ${ }^{1}$, Sadiya Niamath ${ }^{1}$, Mitra Ghosh ${ }^{1}$, Siddhartha Ghosh ${ }^{2}$ \\ 'Department of Histopathology, Apollo Specialty Hospitals, Vanagaram, Chennai -600095. India \\ ${ }^{2}$ Department of Neurosciences, Apollo Specialty Hospitals, Vanagaram, Chennai -600095. India
}

\section{ABSTRACT}

Background: Meningiomas are the most common extra-axial tumours of central nervous system arising from arachnoidal cap cells. The biological behaviour of these tumours is unpredictable because of the tendency of these tumours to recur irrespective of the grade. However, WHO grading is the most useful morphological predictor of recurrence. Additional prognostic parameters like Ki67 proliferation index and progesterone receptor status are useful in predicting the risk of recurrence. This study was undertaken to evaluate the spectrum of Ki67 proliferation index in various grades of meningiomas and to correlate these findings with the hormone receptor status.

Methods: In this study 225 cases of meningiomas, over 6 yrs period, were studied which included grade 1 and grade 2 meningiomas. The relation between Grade, Ki67 proliferation index and progesterone receptor status was studied.

Result: We found a significant positive correlation between grade and Ki67 proliferation index at 0.01 level and significant negative correlation between Grade and progesterone receptor status at 0.05 level. There was also significant negative correlation between progesterone receptor status and Ki67 proliferation index in cases with progesterone receptor staining score of 6 to 12 . Many of the grade 1 meningiomas also showed a higher Ki67 proliferation index

Conclusion: In this study we conclude that, PR and Ki67 Proliferation index are useful supplements of routine histopathological assessment of meningiomas and can be used as prognostic indicators regarding behavior and response to treatment.

Keywords: Hormone Receptors, Progesterone Receptor, Ki67 Proliferation Index, Atypical Meningioma

\section{Introduction}

Meningiomas are the most common central nervous system (CNS) tumours ${ }^{[1]}$ and the most common of the extra-axial tumors which are derived from arachnoidal cap cells. They occur with a frequency of $19 \%$ at intracranial and $25 \%$ at spinal localisations. ${ }^{[1]}$ Most of them are benign, slow-growing neoplasms. According to 2016 WHO classification of CNS tumours, the various subtypes are broadly categorized into 3 grades, Grade 1, Grade 2 and Grade 3 depending on the morphology and biological behavior of these subtypes. Some histological variants of meningioma are more likely to recur. However, overall, WHO grade is the most useful morphological predictor of recurrence. Additional prognostic parameters include Ki67 proliferation index (Ki67 PI) and hormone receptor status. The presence of hormonal receptors i. e. Estrogen and Progesterone receptors (ER and PR) would help for hormonal manipulation of meningiomas in patients with recurrence, incomplete surgical resection and in inaccessible tumors. This study was undertaken to evaluate the spectrum of Ki67 PI in various grades of meningiomas and to correlate these findings with the hormone receptor status.

\section{Materials and Methods}

This is a prospective study which included 225 cases of meningiomas diagnosed during the period from 2013 to 2018. Clinical details were obtained from hospital records and requisition forms received in histopathology department. The specimens were routinely processed and 3 to 4 micron thick sections were made from formalin-fixed paraffin embedded blocks. These sections were stained with Haematoxylin and Eosin. All the meningiomas were histologically graded according to 2016 WHO grading system. Ki67 PI and ER, PR expression were studied by immunohistochemistry using peroxidase method. For ER \& PR, Rabbit monoclonal antibody clone EP1 and EP2 from Pathnsitu were used. For Ki 67 proliferation index, Mouse monoclonal antibody clone GM001 from Pathnsitu was used. The results of receptor status was interpreted by a semi-quantitative scoring scale as described by Roser et al. ${ }^{[1]}$ Staining intensity was graded as 0 - absent, 1-weak, 2-moderate, 3-strong. With respect to percentage of positive tumor cells, they were scored as presence of 0 staining, indicating absence; 1 , few positive tumor nuclei $<10 \%$ in the entire section; $2,10-50 \%$ positive nuclei; $3,51-80 \%$ positive tumor nuclei; and $4,>80 \%$ positive 
nuclei. As recommended for breast cancer ${ }^{[1]}$ and verified with meningioma tissue, ${ }^{[2]}$ an immunoreactive score (IRS) was calculated. Tumors with IRS range of 2 or more were considered receptor positive. For assessment of Ki67 PI, areas with the highest density of Ki67 immunostained nuclei were selected, and the Ki67 PI was expressed as a percentage of positively stained cells out of 1000 tumor cells counted. The results were compiled and assessed.

\section{Result}

We studied 225 cases of meningioma over a period of 6 years. F: M ratio was 1.6:1. Age group ranged from 13yrs to $80 y r$. Majority (32\%) were in the age group of $41-50 \mathrm{yrs}$ age. There were $195(87 \%)$ grade 1 and $30(13 \%)$ grade 2 cases. Grade 1 cases included meningothelial, fibroblastic, transitional, psammomatous, secretory, angiomatous and microcystic meningiomas. Grade 2 cases included 27 cases of atypical meningiomas, 2 cases of clear cell and 1 case of chordoid meningiomas. There was no grade 3 meningiomas encountered during the study period. Meningothelial meningioma was the most common histological subtype (44\%). PR positivity was more common in meningothelial subtype (Table 1). Mean Ki67 PI was 3.3\% in grade 1 and $10.4 \%$ in grade 2 meningiomas i. e. grade 2 meningiomas showed significantly higher mean Ki 67 PI compared to grade 1 cases (Table 2). There was significant positive correlation between grade and Ki67 PI at 0.01 level using Pearson correlation tests $(\mathrm{r}$ value $=0.5$ ). All the 225 cases were ER negative. PR was positive in $167(74 \%)$ cases. Percentage of PR positive cases in females was $75.2 \%$ and in males it was $72.7 \%$ (Table 2). There was no statistically significant correlation between age, sex and PR status or grade. Among the grade 1 cases, $75.4 \%$ cases were PR positive and among grade $2,66.6 \%$ cases were PR positive. There was significant negative correlation between grade and PR status at 0.05 level using pearson correlation tests $(\mathrm{r}$ value $=-0.2)$ (Table 2 ). There was weak negative correlation between Ki67 PI and PR status ( $\mathrm{r}$ value= -0.1). We observed a significant negative correlation between the cases with higher PR score (6-12) and Ki67 PI at 0.05 level using pearson correlation tests $(\mathrm{r}$ value $=$ -0.2) (Table 3). 12 cases of recurrent meningiomas were encountered which included 9 cases of grade 1 and 3 cases of grade 2 meningiomas. Mean Ki67 PI in recurrent grade 1 meningiomas was 5.0\%. Mean Ki67 PI in nonrecurrent grade 1 cases was 3.2\%. We observed a significant negative correlation between PR score and Ki67 PI in recurrent meningiomas at 0.05 level using pearson correlation tests ( $\mathrm{r}$ value $=-0.4)$. There was no correlation between site and Ki67 PI or PR status.

Table 1: PR positivity in various histological types of meningiomas.

\begin{tabular}{|c|c|c|}
\hline Histological type & No of cases & No PR positive cases \\
\hline Meningothelial & 100 & 79 \\
\hline Fibroblastic & 18 & 33 \\
\hline Transitional & 46 & 7 \\
\hline Psammomatous & 9 & 13 \\
\hline Angiomatous & 17 & 3 \\
\hline Secretory & 4 & 1 \\
\hline Microcystic & 1 & 0 \\
\hline Clear cell & 2 & 0 \\
\hline Chordoid & 1 & 20 \\
\hline Atypical & 27 & \\
\hline
\end{tabular}

Table 2: PR positivity and mean Ki67 PI in meningiomas.

\begin{tabular}{|c|c|c|c|c|}
\hline & PR positive & PR negative & $\begin{array}{c}\text { Percentage of PR } \\
\text { positive cases }\end{array}$ & Mean Ki67 PI \\
\hline Males & 64 & 24 & $72.7 \%$ & $4.7 \%$ \\
\hline Females & 103 & 34 & $75.2 \%$ & $3.9 \%$ \\
\hline Grade 1 & 147 & 48 & $75.4 \%$ & $3.3 \%$ \\
\hline Grade 2 & 20 & 10 & $66.6 \%$ & $10.4 \%$ \\
\hline
\end{tabular}

Table 3: Correlation between PR score and Ki67 PI.

\begin{tabular}{|c|c|c|c|}
\hline PR score & PR positive cases & Mean IRS & Mean Ki67 PI \\
\hline $2-5$ & 60 & 3 & $3.8 \%$ \\
\hline $6-12$ & 107 & 9 & $4.2 \%$ \\
\hline Total & 167 & & \\
\hline
\end{tabular}




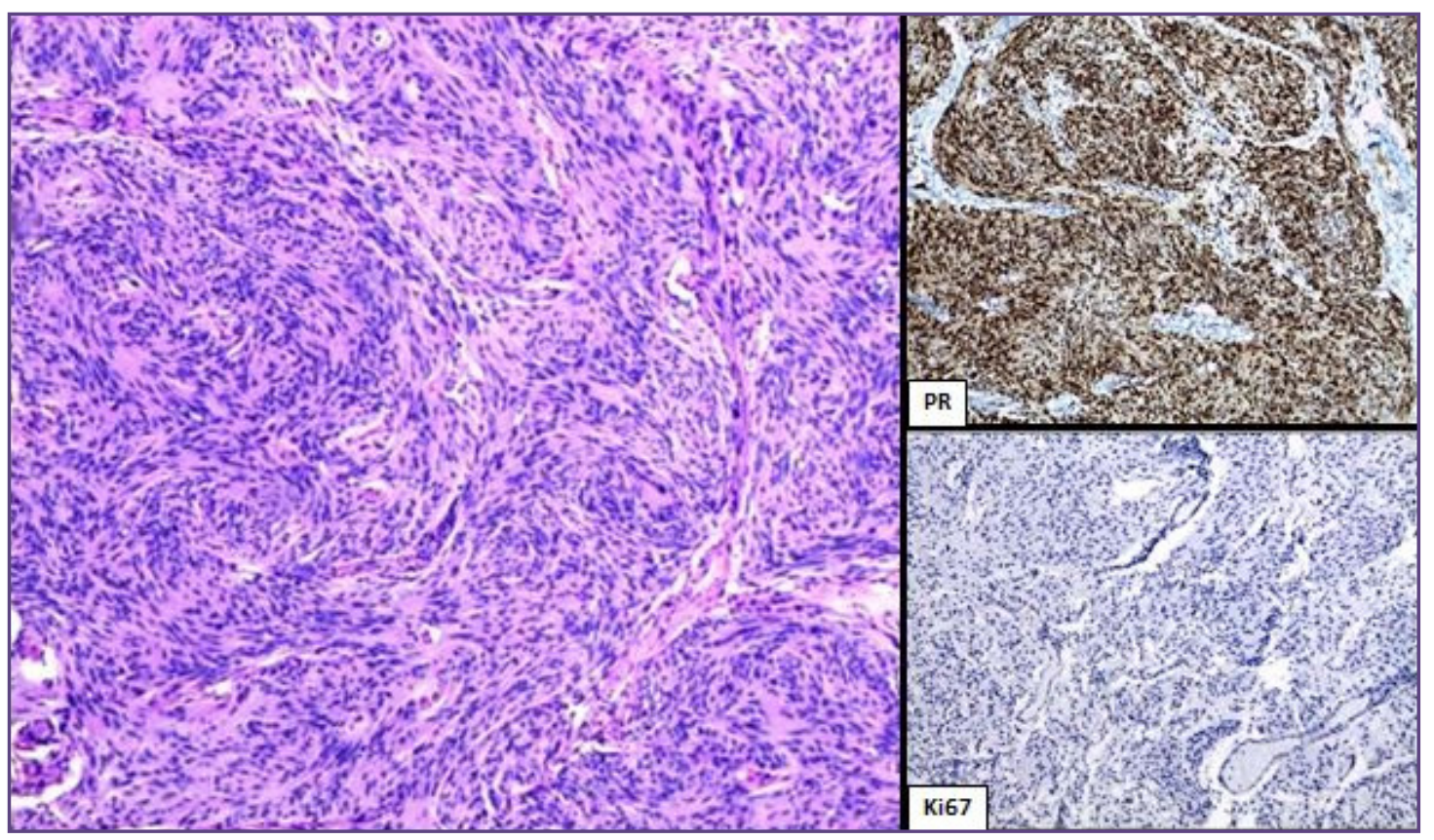

Fig. 1: Grade 1 meningioma with high PR score and low Ki67 PI (H \& E stain, 100X).

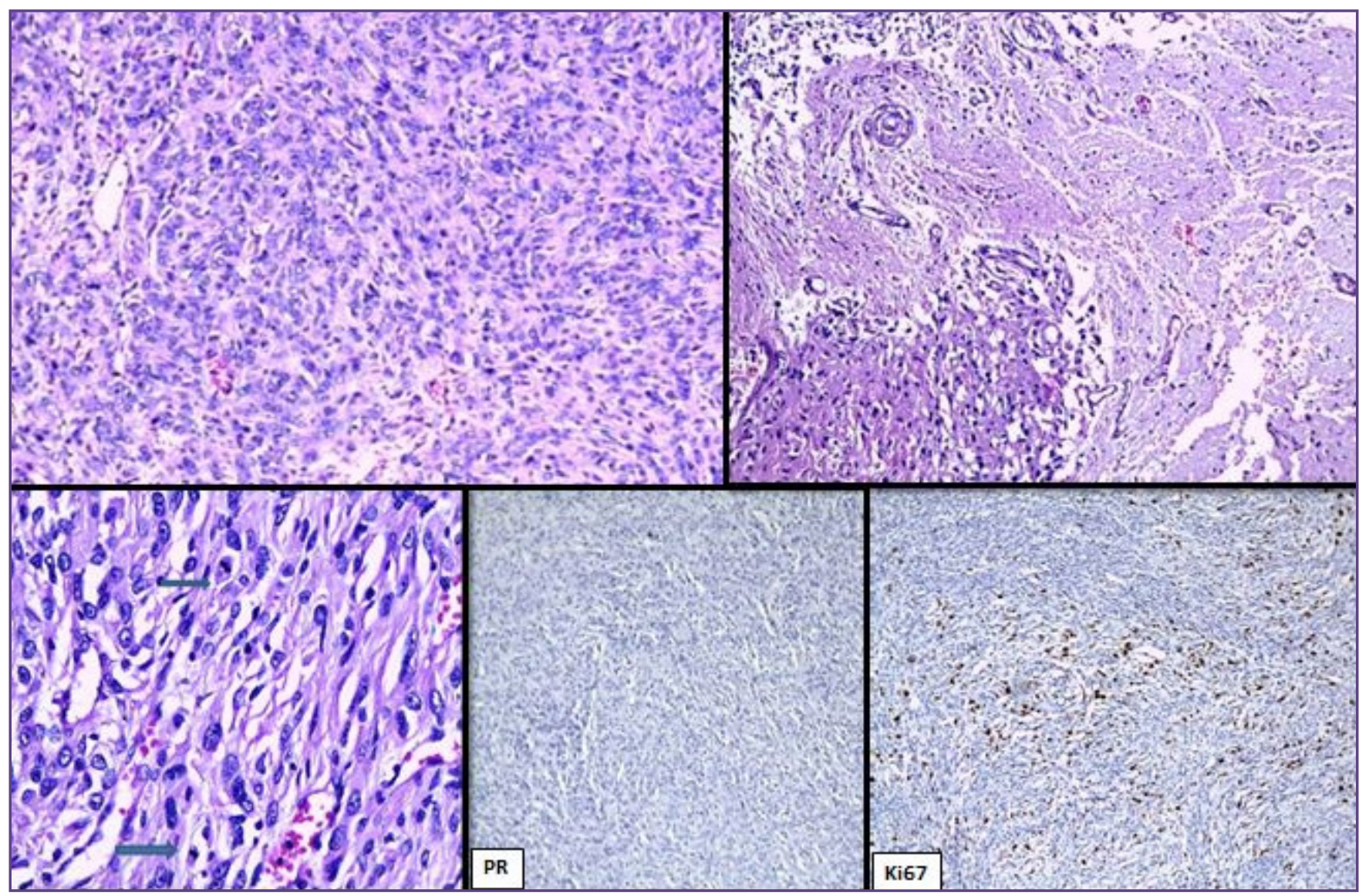

Fig. 2: Grade 2 meningioma with negative PR and high Ki67 PI (arrows - mitoses, asterisk- brain invasion) (H \& E stain, 100X, 400X). 


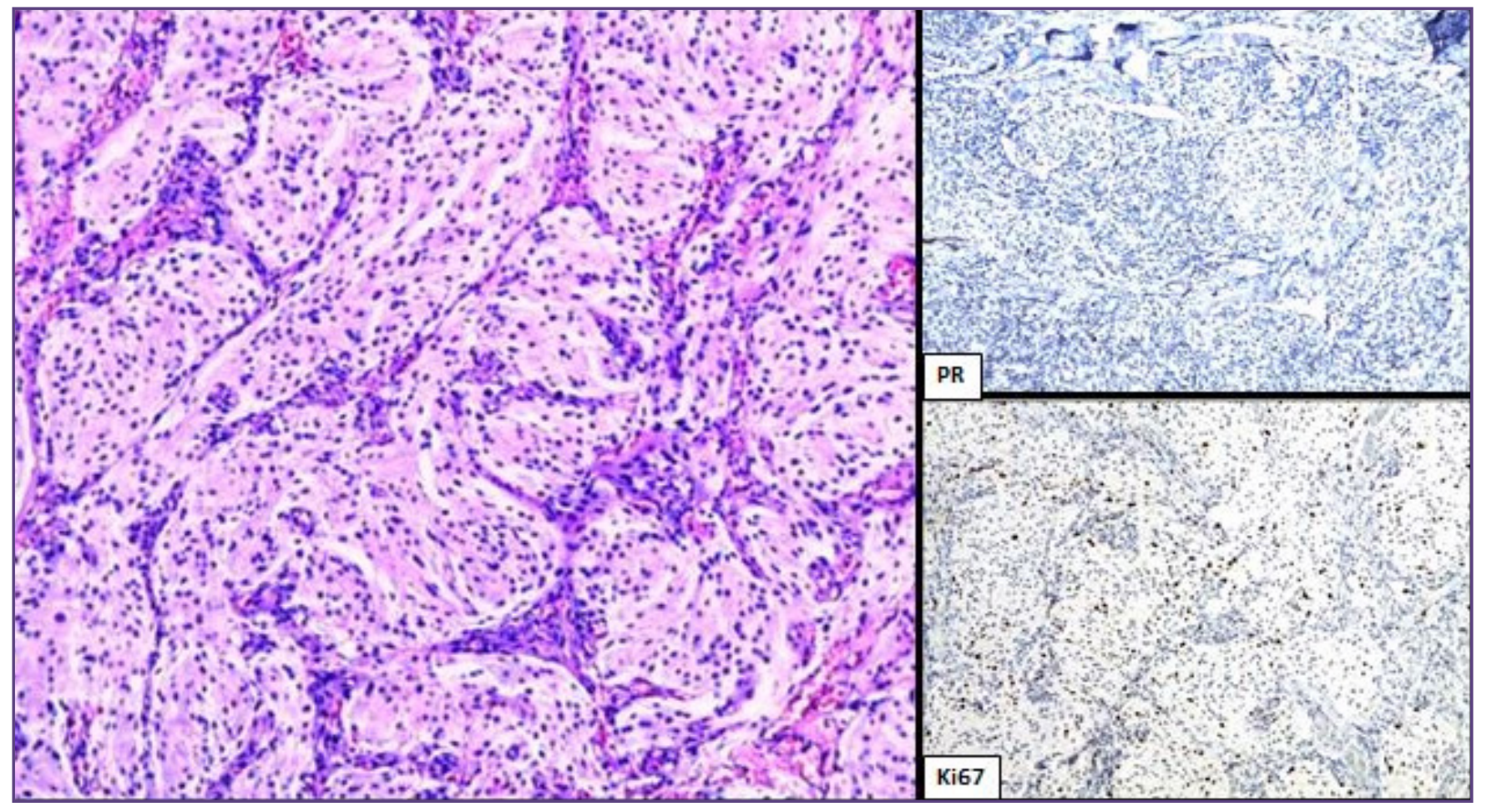

Fig. 3: Grade 1 meningioma with negative PR and high Ki67 PI (H \& E stain, 100X).

\section{Discussion}

Hormone receptors in meningiomas were first described by Donnel et al in 1979 using receptor binding assays. ${ }^{[3,4]}$ Since then, many authors have studied the relation between sex hormone receptors and meningiomas. ${ }^{[5-11]}$ It is assumed that sex steroid hormones may influence the growth of meningiomas because of higher incidence of meningiomas among women, their behaviour during pregnancy, and the reported epidemiological link between meningiomas and breast carcinomas. ${ }^{[1]}$ Since the meningiomas show variable growth potential, and even the WHO microscopic morphological classification frequently fails to predict their clinical behaviour, quantifying the hormonal status of the tumor may help to predict its biological behaviour and provide options for further treatments. It is generally agreed that most meningiomas express PR but are devoid of ER. As with many other tumors, Ki67 PI provides additional information regarding the proliferation index. ${ }^{[2,10]}$

In this study, we studied the hormone receptor status and Ki67 PI in meningomas over a period of 6 years which included 225 cases. Majority of the patients were in the age group of 41-50 yrs and meningothelial meningioma was the most common subtype. F: M ratio was 1.6:1. All the cases were ER negative. PR was positive in $74 \%$ of cases. Some authors demonstrated the presence of the PR positive meningiomas using different methods such as a hormone binding assay or Enzyme immunoassay, or immunohistochemistry. ${ }^{[12]} \mathrm{Khalid}^{[13]}$ reported that all cases were positive for the PR. Hsu et al ${ }^{[14]}$, reported that nuclear staining for the PR was found in 83\%, and Perrot-Applanat et $\mathrm{a}^{[10]}$, noted that, using immunohistochemical method, the PR was found to be present in $72 \%$ of meningiomas.

We found a higher incidence of meningiomas in females (F:M ratio, 1.6:1) but there was no statististically significant difference in PR status, between males and females. Percentage of PR positive cases in females was $75.2 \%$ and in males it was $72.7 \%$. There was no statistically significant difference between PR status and age, sex and histological type. This was in accordance with other studies where the authors have reported that the presence of the PR in meningiomas did not correlate with the age or sex of the patients. ${ }^{[2,10,13-20]}$ Brandis et $\mathrm{al}^{[2]}$ noted that $60 \%$ of the female and $62.5 \%$ of the male patients had the PR expression.

There are studies where they found a clear relationship between the presence of the PR and the histological type of the tumor. ${ }^{[10,15,21,22]}$ Horsfall et a ${ }^{[21]}$, reported an increased presence of the PR in the meningothelial type. Markwalder et $\mathrm{al}^{[15]}$ also noted that the PR expression was associated with certain histological features, with a predominance of PR positivity in the meningothelial subtype. PerrotApplanat et $\mathrm{a}^{\left[{ }^{10]}\right.}$ observed that the PR immunostaining 
was found more frequently in the meningothelial and in the transitional than in the fibroblastic histological types. In the present study, we found that PR positivity was more common in meningothelial subtype (47\%). Carroll et al ${ }^{[23]}$ and Schrell et $\mathrm{al}^{[24]}$ did not find any correlation between histological type and PR status.

In our study PR positivity was higher in grade 1 meningiomas compared to grade 2 meningiomas. Among the grade 1 cases $75.4 \%$ cases were PR positive and among grade $2,66.6 \%$ cases were PR positive. There was significant negative correlation between grade and PR status (Fig 1,2). This is similar to study done by Roser et $\mathrm{al}^{[1]}$ who confirmed the presence of significantly higher PR values in benign meningiomas compared with WHO grade II or III tumors. Cahill et $\mathrm{al}^{[3]}$ and Brandis et al ${ }^{[2]}$ reported that malignant meningiomas are devoid of PR and ER. Many authors demonstrated a close correlation between the PR status and the tumor differentiation, and noted that most non-benign histological subtypes of meningiomas were negative for the PR. ${ }^{[2,9,14,22,25]}$ Hsu et al ${ }^{[14]}$ noted an inverse correlation between the tumor grade and the PR staining score, and concluded that an absence of the PR was significant factor for shorter disease-free intervals. Brandis et $\mathrm{al}^{[2]}$ also found that non-benign variants more frequently showed an absence of the PR. They concluded that the PR status in meningiomas was related to the tumor differentiation and might be of prognostic value with regard to biological behavior and clinical outcome. Similarly, Lesch et $\mathrm{al}^{[26]}$ and Olson ${ }^{[25]}$ found significantly lower PR levels in atypical and malignant meningiomas. But, other studies ${ }^{[16,23,27]}$ showed no relationship between the tumor grade and the presence of the PR.

In our study Ki67 PI of all the cases were analyzed. Mean Ki67 PI was 3.5\% in grade 1 and $10.4 \%$ in grade 2 meningiomas i. e. grade 2 meningiomas showed significantly higher mean $\mathrm{Ki} 67 \mathrm{PI}$ compared to grade 1 cases (Fig1,2). There was significant positive correlation between grade and Ki67 PI. Roser et $\mathrm{al}^{[1]}$ proposed that PR status affected survival only in combination with the proliferation marker ki-67.

In our study the mean Ki67 PI in PR positive and PR negative meningiomas was $4.1 \%$ and $4.5 \%$ respectively. We observed a significant negative correlation between the cases with higher PR score (6-12) and Ki67 PI at 0.05 level using pearson correlation tests $(\mathrm{r}$ value $=-0.2)$. There was decrease in PR score as Ki 67 PI increased (Fig 3). This is in accordance with Nagashima et $\mathrm{al}^{[9]}$, reported that the Ki-67 staining index of the PR positive meningiomas were significantly lower than that of the PR negative meningiomas. They insisted that the PR status might be closely related to the growth potentials of the meningiomas. Markwalder et a ${ }^{[11]}$ and Perrot-Applanat et a ${ }^{[10]}$ noted that there was no significant correlation between the PR status and the Ki-67 staining index.

Maiuri et $\mathrm{al}^{[28]}$ showed that proliferative index and PR status have a strong predictive value. Whittle et al ${ }^{[29]}$ showed that PR negative meningiomas were biologically more aggressive than PR positive ones. Wolfsberger et $\mathrm{al}^{[30]}$ found that the highest PR index is observed in patients under the age of 50 years with WHO grade I meningiomas of the meningothelial subtype and low cell proliferation index.

In our study we encountered 9 cases of recurrent grade 1 meningiomas. Mean Ki $67 \mathrm{PI}$ in recurrent grade 1 meningiomas higher $(5.0 \%)$ compared to nonrecurrent grade 1 cases $(3.2 \%)$. Yamasaki et al ${ }^{[31]}$ reported that $\mathrm{Ki} 67$ PI of recurrent tumors were higher. There was significant negative correlation between Ki67 PI and PR score of recurrent cases at 0.05 level $(\mathrm{r}$ value $=-0.4$ ). All these patients presented to our hospital during the recurrence, there were no details available regarding previous excision and histology.

Walter et $\mathrm{al}^{[32]}$ has shown that preoperative administration of medroxy progesterone in patients with meningiomas that have positive PR receptors would show better clinical response when compared to patients who had tumor cells that were without PR receptors. Vissa shanthi et al ${ }^{[4]}$ found that the tumors with high proliferative activity showed low PR expression. They proposed that though surgery is the treatment for the meningiomas, in some cases where tumor is not accessible to surgery or in elderly patients or in malignant tumors where complete removal is not possible due to invasion into the adjacent structures, antiprogesterone agents can be used in addition to radiotherapy. Taghipour et $\mathrm{al}^{[33]}$ reported that positive progesterone receptor status is associated with better prognosis. Wahab et $\mathrm{al}^{[34]}$ reported that the tumors with positive progesterone receptors had less recurrence rate. However studies done by Roser et $\mathrm{al}^{[1]}$ suggested that only PR status cannot predict the prognosis in these tumors. The proliferative index should be used in combination with PR status to predict the prognosis of meningiomas. In the study conducted by Vibha Dutta et $\mathrm{al}^{[35]}$, they suggested that PR status is an important prognostic factor in meningioma, more so in combination with proliferative index.

In our study all the cases were followed up with clinical and radiological assessment to look for recurrence. The average follow up period ranged from 6 months to 5 years. Accept 9 cases of recurrent meningiomas which presented 
to us during recurrence, no other cases presented with recurrence during the study period.

\section{Conclusion}

Meningiomas are the tumours showing variable growth potential. Since benign(grade1) meningiomas may also show recurrence, the recurrence cannot be predicted by histomorphological features alone. Cell proliferation indices like Ki67 PI along with PR status can be used as a guide in grading of meningioma and therefore in prediction the recurrence potential of them. Our study suggests that PR status, in combination with Ki67 PI, is an important prognostic factor in meningioma. Meningiomas with higher proliferation index and negative PR have higher recurrence potential. But the PR status alone cannot be used to predict behaviour in meningiomas and should not influence therapeutic strategies. Studies have shown that use of antiprogesterone agents might result in better clinical response. But these studies are yet to be verified. In this study we propose that, PR and Ki67 PI immunohistochemical staining are useful supplements of routine histopathological assessment of meningiomas and can be used as prognostic indicators regarding behaviour and response to treatment.

\section{Acknowledgements}

We sincerely acknowledge our technical staff, Mrs P Shivashankari, Mr R Bhuvaneshwaran, Mrs Lavanya Latha, Mrs J Rukmani for their technical help.

\section{References}

1. Roser F, Nakamura M, Bellinzona M, Rosahl SK, Ostertag $\mathrm{H}$, Samii M. The prognostic value of progesterone receptor status in meningiomas. J Clin Pathol 2004; 57: 1033-7.

2. Brandis A, Mirzai S, Tatagiba M, Walter GF, Samii M, Ostertag H. Immunohistochemical detection of female sex hormone receptors in meningiomas: correlation with clinical and histological features. Neurosurgery 1993; 33: 212-7.

3. Cahill DW, Bashirelahi N, Solomon LW, Dalton T, Salcman M, Ducker TB. Estrogen and Progesterone receptors in meningiomas. J Neurosurg 1984; 60:985-93.

4. Shanthi V, Grandhi B, Rao NM, Rao BS, Reddy VM. Assessing the Prognostic Importance of ER, PR Expression in Meningiomas by Comparing with Proliferative Rate Using Ki67. Indian Journal of Pathology: Research and Practice 2017; 6:431-4.

5. Gursan N, Gundogdu C, Albayrak A, Kabalar ME. Immunohistochemical detection of progesterone receptors and the correlation with Ki-67 labeling indices in paraffinembedded sections of meningiomas. Int $\mathrm{J}$ Neurosci 2002;112:463-70.

6. Strik HM, Strobelt I, Pietsch-Breitfeld B, Iglesias-Rozas JR, Will B, Meyermann R. The impact of progesterone receptor expression on relapse in the long-term clinical course of 93 benign meningiomas. In Vivo 2002;16:265-70.

7. Blankenstein MA, Verheijen FM, Jacobs JM, Donker TH, van Duijnhoven MW, Thijssen JH. Occurrence, regulation, and significance of progesterone receptors in human meningioma. Steroids 2000;65:795-800.

8. Fewings PE, Battersby RD, Timperley WR. Long-term follow up of progesterone receptor status in benign meningioma: a prognostic indicator of recurrence? J Neurosurg 2000;92:401-5.

9. Nagashima G, Aoyagi M, Wakimoto H, Tamaki M, Ohno K, Hirakawa K. Immunohistochemical detection of progesterone receptors and the correlation with $\mathrm{Ki}-67$ labeling indices in paraffin-embedded sections of meningiomas. Neurosurgery 1995;37:478-82.

10. Perrot-Applanat M, Groyer-Picard MT, Kujas M. Immunocytochemical study of progesterone receptor in human meningioma. Acta Neurochir 1992;115:20-30.

11. Markwalder TM, Gerber HA, Waelti E, Schaffner T, Markwalder RV. Hormonotherapy of meningiomas with medroxyprogesterone acetate: Immunohistochemical demonstration of the effect of medroxyprogesterone acetate on growth fractions of meningioma cells using the monoclonal antibody Ki-67. Surg Neurol 1988;30:97-101.

12. Halper J, Colvard DS, Scheithauer BW, Jiang NS, Press MF, Graham ML 2nd et al. Estrogen and progesterone receptors in meningiomas: Comparison of nuclear binding, dextrancoated charcoal, and immunoperoxi-dase staining assays. Neurosurgery 1989;25:546-53.

13. Khalid H. Immunohistochemical study of estrogen receptor related antigen, progesterone, and estrogen receptors in human intracranial meningiomas. Cancer 1994;74:679-85.

14. Hsu DW, Efird JT, Tessa Hedley-Whyte E. Progesterone and estrogen receptors in meningiomas. Prognostic considerations. J Neurosurg 1997;86:113-20.

15. Markwalder TM, Zava DT, Goldhirsch A, Markwalder RV. Estrogen and progesterone receptors in meningiomas in relation to clinical and pathologic features. Surg Neurol 1983;20:42-7.

16. Blaauw G, Blankenstein MA, Lamberts SW. Sex steroid receptors in human meningiomas. Acta Neurochir 1986;79:42-7.

17. Hayward E, Whitwell H, Paul KS, Barnes DM. Steroid receptors in human meningiomas. Clin Neuropharmacol 1984;7:351-6.

18. Ironside JW, Battersby RDE, Dangerfield VJM, Parsons MA, Timperley WR, JCE Underwood. Cryostat section assasy of estrogen and progesterone receptors in meningiomas: A clinicopathological study. J Clin Pathol 1986;39:44-50.

19. Matsuda Y, Kawamoto K, Kiya K, Kurisu K, Sugiyama $\mathrm{K}$, Uozumi T. Antitumor effects of antiprogesterones on human meningioma cells in vitro and in vivo. J Neurosurg 1994;80:527-34. 
20. Whittle IR, Foo MS, Besser M, Vanderfield GK. Progesterone and estrogen receptors in meningiomas: Biochemical and clinicopathological considerations. Aust N Z J Surg 1984;54;325-30.

21. Horsfall DJ, Goldsmith KG, Ricciardelli C, Skinner JM, Tilley WD, Marshall VR. Steroid hormone and epidermal growth factor receptors in meningiomas. Aust N Z J Surg 1989;59:881-88.

22. Schlegel J, Ullrich B, Stumm G, Gass P. Expression of the cerb B-2-encoded oncoprotein and progesterone receptor in human meningiomas. Acta Neuropathol 1993;86:473-79.

23. Carroll RS, Glowacka D, Dashner K, Black PM. Progesterone receptor expression in meningiomas. Cancer Res 1993;53:1312-6.

24. Schrell UM, Adams EF, Fahlbusch R, Greb R, Jirikowski $\mathrm{G}$, Prior $\mathrm{R}$ et al. Hormonal dependency of cerebral meningiomas. Part 1: Female sex steroid receptors and thier significance as specific markers for adjuvant medical therapy. J Neurosurg 1990;73:743-9.

25. Olson JJ. Laboratory evidence for the hormonal dependency of meningiomas. Human Reprod 1994; 9:195-201.

26. Lesch KP, Gross S. Estrogen receptor immunoreactivity in meningiomas. Comparison with the binding activity of estrogen, progesterone and androgen receptors. J Neurosurg 1987;67:237-43.

27. Schwartz MR, Randolph RL, Cech DA, Rose JE, Panko WB. Steroid hormone binding macromolecules in meningiomas failure to meet criteria of specific receptors. Cancer 1984;53:922-7.
28. Maiuri F, De Caro MB, Esposito F, Cappabianca P, Strazzullo $\mathrm{V}$, Pettinato $\mathrm{G}$ et al. Recurrences of meningiomas: predictive value of pathological features and hormonal and growth factors. J Neurooncol 2007;82:63-8.

29. Whittle IR, Foo MS, Besser M, Vanderfield GK. Progesterone and oestrogen receptors in meningiomas: biochemical and clinicopathological considerations. Aust N Z J Surg 1984;54:325-30.

30. Wolfsberger S, Doostkam S, Boecher-Schwarz HG, Roessler K, van Trotsenburg M, Hainfellner JA et al. Progesteronereceptor index in meningiomas: correlation with clinicopathological parameters and review of the literature. Neurosurg Rev 2004;27:238-45.

31. Yamasaki F, Yoshioka H, Hama S, Sugiyama K, Arita K, Kurisu K. Recurrence of meningiomas. Cancer 2000; 89: 1102-10.

32. Walter LM, Rogers PA, Girling JE. The role of progesterone in endometrial angiogenesis in pregnant and ovariectomised mice. Reproduction 2005; 29:765-7.

33. Taghipour M, Rakei SM, Monabati A, Nahavandi- Nejad M. The role of estrogen and progesterone receptors in grading of the malignancy of meningioma. Iranian Red Crescent Medical journal 2007; 9:17-21.

34. Wahab M, Al-Azzawi F. Meningioma and hormonal influences. Climacteric 2003; 6:285-92

35. Dutta V, Malik A, Topgay T, Deb P. Immunohistochemical Study Characterizing Estrogen and Progesterone Receptors Status in Meningiomas and Correlation with MIB-1 Labeling index. Indian Journal of Pathology: Research and Practice 2012; 1:61-6.

*Corresponding author:

Dr. Rajeshwari B, Associate consultant, Department of Histopathology, Apollo speciality hospitals, Vanagaram. Ayanambakkam Chennai - 600095 INDIA Phone: +919159955741

Email: rajeshwari.buttannavar@gmail.com

Financial or other Competing Interests: None. 